\title{
Knowledge of palliative care and preference of end of life care: a cross-sectional survey of residents in the Chinese socio-cultural background of Macao
}

\author{
Kuai In Tam, Sok Leng Che, Mingxia Zhu and Sok Man Leong*
}

\begin{abstract}
Background: Since the establishment of a hospice in the year 2000 and the development of a palliative care ward in 2019, there is no study examining public's knowledge of palliative care, nor preference of end of life care in Macao.

Aim: Targeting Chinese residents of Macao, the current study has 3 goals: i) to understand the level of knowledge of palliative care, ii) to explore the preference of end of life treatments, and iii) to identify the associated factors of the preference of end of life treatments.

Methods: A cross-sectional questionnaire survey was conducted using a structured questionnaire. The study employed non-probability quota sampling through which Macao residents aged 18 and above were recruited between July and September 2020.
\end{abstract}

Results: A total of 737 responses were valid. The average correct rate of palliative care knowledge ranged from $40.4 \%$ to $85.5 \%$. Pertaining to end of life treatments, $62.0 \%$ of the respondents chose comfort care. However, almost half of the respondents agreed that life-sustaining treatments should not be stopped under any circumstances. Respondents who scored higher in palliative care knowledge and those with secondary and tertiary education were associated factors of choosing comfort care rather than life-sustaining treatments. In addition, respondents who agreed that futile life-sustaining treatments should be stopped were also associated with preference for comfort care.

Conclusion: The understanding of palliative care amongst Macao residents is inadequate. Despite the public's inclination towards comfort care, it is generally believed that life-sustaining treatments should not be stopped at the end of life. The study results suggest that not only the knowledge of palliative care should be enhanced amongst the general public in Macao, but information about life-sustaining treatments should also be offered to patients and families by healthcare professionals, in aiding end of life treatment decision making.

Keywords: End of life care, Palliative care, Chinese culture, End of life care preferences, Life-sustaining treatments

*Correspondence: Ism@kwnc.edu.mo

Kiang Wu Nursing College of Macau, Est. Repouso No. 35, R/C, Macao SAR, China

\begin{abstract}
Background
Macao's earliest implementation of palliative and end of life (EoL) care began when the first hospice was established in the year 2000. There has been very limited advancement since then, and the latest being the establishment of a palliative care ward within the government hospital in 2019, both the hospice and the palliative care
\end{abstract}


ward are fully funded by the Macao government. While there is a limited extent of home visit offered by the hospice, the main focus of palliative care in Macao has remained on the inpatient service.

With respect to government policy, the Macao government formulated a ten-year action plan to develop and improve elderly care services in 2016, and the action plan emphasised the expansion of the existing palliative and EoL care services as well as the development of EoL care services in nursing homes [1]. Regarding legislations on EoL issues, there is no advance directives legislation in Macao. Patients and their families can decide to sign an agreement stating the decision to reject resuscitation or other life-sustaining treatments (LST). However, the agreement is based primarily on hospital's internal policy whose nature is conceptually different from advance directives, and the agreement is not legally binding.

In terms of knowledge provision, the ten-year plan has made clear goals in promoting life and death education amongst the public, and enhancing the knowledge level of palliative and EoL care of the healthcare workforce [1]. Whilst it is important to improve palliative and EoL care services, it is equally important to raise people's awareness and understanding about such care. Although public education of life and death issues was included as part of the short-term goals between 2016 and 2017, there has not been any official review evaluating the actual outcomes of the ten-year action plan in Macao. This situation is worth noting, especially when the lack of knowledge was found to be the key impediments to the overall development and acceptance of palliative and EoL care across different regions [2-9].

Literature in the subject of public knowledge of palliative and EoL care is found to be relatively limited; there are only a handful of studies that have conducted this type of research in specific locations, including Northern Ireland, Ireland, Sweden, Italy, Australia, Scotland, the United States, Hong Kong and Japan [2-7, 10-13]. Most of the available studies revealed that knowledge of palliative and EoL care amongst the general population is inadequate. Temel et al. [12]'s study found that around $70 \%$ of the US respondents do not have adequate knowledge about palliative care; Westerlund et al. [4] and Hirai et al. [3] shared similar findings in which respondents showed limited understanding of palliative and EoL care. Amongst Chinese population, recent studies conducted in Hangzhou and Hong Kong also found that Chinese respondents have little understanding about palliative and EoL care $[14,15]$.

In Macao, there has been some, though limited, research effort in exploring how people in Macao perceived EoL decision making. A study by Ho and Sanders [16] found that older Chinese in Macao tended to opt for institutionalised care at the EoL as they did not want to be a burden to family. However, Ho and Sanders [16]'s study was not focused on the preference relating to EoL care, rather, its primary focus was on EoL decision making amongst older Chinese in Macao. Nevertheless, Ho and Sanders [16]'s study was the first of its kind to explore people's thoughts and decision making about EoL issues in Macao.

Taking into consideration adequate understanding of palliative and EoL care was shown to encourage terminally ill patients to choose EoL care, and thereby improve their quality of life at the end of their lives [12], this research aimed to fill this knowledge gap by exploring the public's knowledge of palliative care, and their preferences regarding EoL care within the Chinese sociocultural environment of Macao. More significantly, our study aimed to investigate elements that could potentially influence people's decision between choosing palliative care or LST.

\section{Methods \\ Research design}

The study was a cross-sectional survey using a structured questionnaire.

\section{Sample}

The study employed non-probability quota sampling according to the demographic statistics at the end of 2019 in Macao [17]. Macao residents aged eighteen and above, and are able to sufficiently understand informed consent materials and questionnaire content were recruited. Exclusion criteria for this study included: i) Individuals who have severe hearing impairment and individuals who are unable to communicate, and ii) Individuals who may feel their levels of distress may hinder capacity for informed consent and/or consider participation overwhelming.

The sample size for this cross-sectional survey study was calculated according to Charan \& Biswas [18] and Pourhoseingholi et al. [19]'s sample size calculation. The significance criterion in this study was set to 0.5 , with the absolute error of $5 \%$ and at type 1 error of $5 \%$. The study aimed to recruit at least 384 respondents.

\section{Recruitment}

In applying the quota sampling, the study advertised and recruited respondents from tertiary education institutions, social media platforms and two of the largest social organisations for adults with different backgrounds across different age groups; self-administered electronic version of the questionnaire was completed through the online platform Survey Monkey (https://www.surve ymonkey.com/). The Internet Protocol (I.P.) address of 
respondents was the only linked identifier which made the survey partly anonymised. For individuals aged 60 and above, recruitment was conducted through day centres for older adults, and the questionnaire was completed face-to-face by trained interviewers. Data was collected between July and September 2020.

\section{Questionnaire}

Having reviewed a number of similar studies, the study referenced the questionnaires developed by Mcllfatrick et al. [6], Chung et al. [7] and Hsu et al. [20] enquiring Macao people's perceptions of palliative and EoL care. The questionnaire was assessed by three experts in the field of palliative and EoL care from Beijing, Macao and Hong Kong. The questionnaire was revised according to the experts' comments. The final questionnaire included three sections.

The first section collected the sociodemographic data of respondents, including age, gender, education level, marital status, religious beliefs, employment status, occupation and average monthly income in the past year. The second section focused on the knowledge of palliative care, enquiring respondents whether they have heard of palliative care and inviting them to choose from the following options "I have heard about it and know it very well", "I have heard about it but don't know it well", "I have not heard of it before but want to know more", or "I have not heard of it before and I don't want to know more". Moreover, in this section, a 9-item scale was structured after adopting the questions from existing literature $[6,7$, $20]$ and took into considerations the sociocultural conditions of Macao. The 9-item scale was devised to understand respondents' knowledge regarding the goal and service of palliative care, and the reliability of the scale was checked in the pilot stage, with the Item-Content Validity Index of 0.97 and the Cronbach's $\alpha$ of 0.75 , indicating that the scale was primarily suitable to enquire people's knowledge of palliative care.

In the third section, respondents' preference towards EoL treatment options was explored with two questions. The first question asked: "If the doctor has diagnosed you with an incurable illness, and you are estimated to have less than 6 months to live, which of the following would you choose?" Respondents were presented with 4 options: i) "I will accept all life prolonging treatments, even though discomfort or suffering may occur during the treatment process", ii) "I will accept treatments that can ease pain and suffering, or alleviate discomfort caused by symptoms, even though my life may not be extended", iii) "I don't know/ I don't have a decision", iv) "I don't want to answer". The second question asked: "If the doctor has diagnosed you with an incurable illness, and you are estimated to have less than 6 months to live, would you agree that all LST should not be stopped under any circumstances?", respondents were then presented with 5 statements: i) strongly agree, ii) agree, iii) neither agree nor disagree, vi) disagree and v) strongly disagree.

\section{Ethics}

The study has obtained ethical approval from Kiang Wu Nursing College of Macau. All methods were employed in accordance with relevant guidelines and regulations. Respondents were asked to give their consent prior to the commencement of the questionnaire survey. Respondents were explained that they could stop or withdraw from the survey any time.

\section{Statistical analysis}

Raw data were initially revised and coded in Microsoft Office Excel 2013. The study utilised Statistical Package for the Social Sciences Version 22 (SPSS, v22) for data manipulation and subsequent analysis. Descriptive analyses were performed on the collected demographic data, knowledge level of palliative care and attitude towards EoL care. To determine associated factors of palliative care as the preferred form of EoL care, logistic regression models were performed, adjusting for demographic covariates and knowledge level of palliative care, with estimated odds ratio (OR) with their 95\% confidence intervals. The threshold for statistical significance was set to $\mathrm{p}<0.05$. Only respondents who completed the full questionnaire were considered valid for logistic regression. The management of research data and the process of study was performed in full compliance with the requirements stipulated in the internal regulations of the Research Management and Development Department of Kiang Wu Nursing College of Macau.

\section{Results}

\section{Demographic characteristics of study respondents}

The study received a total of 1001 responses in which 737 were valid, the completion rate was $73.6 \%$. Amongst all respondents, $65.0 \%$ of them were female, aged between 19 and $101 ; 66.5 \%$ of respondents were married or cohabited, and $20.9 \%$ of respondents were not married; $56.9 \%$ of the respondents had college level or higher; $24.2 \%$ of respondents were working as professionals and $11.7 \%$ were medical (assistant) professionals. Owing to the dominant hospitality and gaming industry of Macao, $18.0 \%$ of respondents were attendants, $38.5 \%$ of respondents had cared for relatives or friends suffering from terminal illness (Table 1). 
Table 1 Demographic characteristics of respondents $(N=737)$

\begin{tabular}{|c|c|c|}
\hline Variables & $\mathbf{n}$ & $\%$ \\
\hline \multicolumn{3}{|l|}{ Gender } \\
\hline Male & 258 & 35.0 \\
\hline Female & 479 & 65.0 \\
\hline \multicolumn{3}{|l|}{ Age } \\
\hline $18-39$ & 310 & 42.1 \\
\hline $40-64$ & 305 & 41.4 \\
\hline$\geq 65$ & 122 & 16.6 \\
\hline \multicolumn{3}{|l|}{ Education } \\
\hline Primary school or below & 96 & 13.0 \\
\hline Secondary school & 216 & 29.3 \\
\hline Bachelor or above & 419 & 56.9 \\
\hline Other & 6 & 0.8 \\
\hline \multicolumn{3}{|l|}{ Marital status } \\
\hline Not married & 154 & 20.9 \\
\hline Married/ cohabited & 490 & 66.5 \\
\hline Separated/ divorced & 38 & 5.2 \\
\hline Widowed & 55 & 7.5 \\
\hline \multicolumn{3}{|l|}{ Children } \\
\hline Yes & 519 & 70.4 \\
\hline No & 218 & 29.6 \\
\hline \multicolumn{3}{|l|}{ Religious belief } \\
\hline None & 428 & 58.1 \\
\hline Christianity & 121 & 16.4 \\
\hline Buddhism/ Chinese folk beliefs & 188 & 25.5 \\
\hline \multicolumn{3}{|l|}{ Occupation } \\
\hline Professional & 178 & 24.2 \\
\hline Medical (assistant) professional & 86 & 11.7 \\
\hline Technician & 108 & 14.7 \\
\hline Attendant & 133 & 18.0 \\
\hline Disciplined services/ other & 41 & 5.6 \\
\hline Not employed ${ }^{\mathrm{a}}$ & 191 & 25.9 \\
\hline \multicolumn{3}{|c|}{ Average monthly income in the past year } \\
\hline$<9,999$ & 149 & 20.2 \\
\hline $10,000 \sim 19,999$ & 141 & 19.1 \\
\hline $20,000 \sim 29,999$ & 177 & 24.0 \\
\hline$\geqq 30,000$ & 224 & 30.4 \\
\hline No answer & 46 & 6.2 \\
\hline \multicolumn{3}{|c|}{ Cared for relatives or friends suffering from terminal illness } \\
\hline Yes & 284 & 38.5 \\
\hline No & 453 & 61.5 \\
\hline \multicolumn{3}{|l|}{ Self-rated health } \\
\hline Good & 305 & 41.4 \\
\hline Not good & 432 & 58.6 \\
\hline
\end{tabular}

Note: Due to rounding, percentages may not always appear to add up to $100 \%$

a Including student, unemployed, housewife/ househusband and retired

\section{Respondents' knowledge of palliative care}

Over half of the study respondents had heard of the term 'palliative care', however, less than $10 \%$ of them identified themselves to be very knowledgeable about it. There was still over $40 \%$ of study respondents who had no awareness about palliative care (Table 2).

Regarding the understanding of palliative care, the average correct rate of palliative care knowledge was $62.9 \%$ (ranging from $40.4 \%$ to $85.5 \%$ ). The majority of respondents $(85.5 \%)$ understood that the goal of palliative care is to eliminate pain and suffering for patients. Respondents were also able to correctly identify that palliative care satisfies patients' psychological and spiritual needs, and palliative care takes care of patients as well as the need of families. However, almost half of the respondents identified that palliative care is only suitable for terminal cancer patients, and a significant number of respondents $(72.3 \%)$ supported the misconception that palliative care offers no treatment to patients, receiving palliative care equals to waiting for their death (Table 3).

\section{Attitudes towards end of life treatment options}

Table 4 indicates that over half of the study respondents (62.0\%) chose treatments that would alleviate their suffering rather than life-prolonging treatments, even though their limited life might not be extended. Under one-fifth of respondents (18.6\%) had wished to have their lives prolonged at all cost, even though suffering or discomfort might occur during this process. There was also almost one-fifth of respondents who did not know or did not have a decision.

\section{Attitudes towards life-sustaining treatments}

As shown in Table 5, when respondents were asked if they would agree that LST should not be stopped under any circumstances, almost half (44.9\%) of the respondents agreed and strongly agreed. Only a third of the study respondents disagreed and strongly disagreed with the statement (33.4\%). This result is significant in that it indicates conflicting wishes amongst study respondents in Macao regarding EoL treatment options. Whilst the above results show that over half of the study respondents opted for comfort care at the end of their lives, a significant portion of them also decided that life should be sustained under any circumstances.

Table 2 Respondents' awareness of palliative care $(N=737)$

\begin{tabular}{lcr}
\hline & $\mathbf{n}$ & $\%$ \\
\hline $\begin{array}{l}\text { Have you heard of palliative care, and how would you describe your } \\
\text { level of knowledge of palliative care? }\end{array}$ & 71 & 9.6 \\
Yes, and very knowledgeable & 337 & 45.7 \\
Yes, but not very knowledgeable & 295 & 40.0 \\
No, but would like to know more & 34 & 4.6 \\
No, and would not like to know & &
\end{tabular}


Table 3 Knowledge of palliative care amongst respondents $(N=737)$

\begin{tabular}{|c|c|c|c|}
\hline & n & $\%$ & Ranking \\
\hline A. Palliative care is only suitable for terminal cancer patients ${ }^{a}$ & 351 & 47.6 & 8 \\
\hline B. Palliative care takes care of patients as well as the need of families & 590 & 80.1 & 3 \\
\hline C. One can only receive palliative care at the Hospice and Palliative Centre ${ }^{a}$ & 298 & 40.4 & 9 \\
\hline D. Patients can still receive palliative care in normal hospital wards & 379 & 51.4 & 6 \\
\hline E. While patients are receiving routine treatments, they can still receive palliative care & 443 & 60.1 & 5 \\
\hline $\begin{array}{l}\text { F. If one receives palliative care, it means healthcare professionals will not give any treatments to } \\
\text { the patients, and letting the patients to "wait for their death"a }\end{array}$ & 533 & 72.3 & 4 \\
\hline G. The purpose of palliative care is to cure patients' illnesses ${ }^{a}$ & 359 & 48.7 & 7 \\
\hline H. The purpose of palliative care is to relieve or eliminate patients'suffering & 630 & 85.5 & 1 \\
\hline I. To satisfy patients' psychological and spiritual needs is part of palliative care & 591 & 80.2 & 2 \\
\hline Average correct rate & & 62.9 & \\
\hline
\end{tabular}

${ }^{\text {a }}$ Reverse coded item

Table 4 Attitudes towards end of life treatment options ( $N=737)$

\begin{tabular}{lc}
\hline & $\mathbf{n}$ \\
\hline If the doctor has diagnosed you with an incurable illness, and you are estimated to have less than 6 months to live, which of the following would you \\
choose? & 137 \\
I will accept all life-prolonging treatments, even though discomfort or suffering may occur during the treatment process & 18.6 \\
I will accept treatments that can ease pain and suffering, or alleviate discomfort caused by symptoms, even though my life may & 457 \\
not be extended & 62.0 \\
I don't know/I don't have a decision & 135 \\
I don't want to answer & 8.3 \\
\hline
\end{tabular}

Table 5 Attitude towards life-sustaining treatments $(N=737)$

\begin{tabular}{lc}
\hline & $\mathbf{n}$ \\
\hline If the doctor has diagnosed you with an incurable illness, and you are estimated to have less than 6 months to live, would you agree that all life- \\
sustaining treatments should not be stopped under any circumstances? & 114 \\
Strongly agree & 217 \\
Agree & 96 \\
Neither agree nor disagree & 210 \\
Disagree & 36.5 \\
Strongly disagree & 64.4 \\
I don't know/ Don't want to answer & 13.0 \\
\hline
\end{tabular}

\section{Factors associated with end of life care preferences}

The level of education amongst respondents was found to influence the preference of EoL care; respondents who had attained secondary education were 2.87 times $(\mathrm{aOR}=2.87, p=0.04)$ more likely to prefer comfort care, while respondents who had undergraduate degree or above were almost 4 times $(\mathrm{aOR}=3.68, p=0.01$ ) more likely to choose comfort care at the EoL when comparing with those with primary education. In addition, knowledge level of palliative care affected EoL treatment options; for every score increased in knowledge level, respondents had $8 \%$ higher odds of choosing comfort care $(p=0.04)$. Regarding attitude towards LST, respondents who did not agree with "LST should not be stopped" were 3 times $(\mathrm{aOR}=3.27, p<0.001)$ more likely to prefer comfort care when comparing with respondents who agreed with LST at the EoL. All other factors were not significantly correlated with EoL treatment options (Table 6).

\section{Discussion}

Our study is, to our knowledge, the first populationbased survey investigating residents' preference of EoL treatment options in Macao. The current study has 
Table 6 Logistic regression models of palliative care as the preferred form of EoL care $(N=632)$

\begin{tabular}{|c|c|c|c|c|c|c|c|}
\hline \multirow[t]{2}{*}{ Variables } & \multirow[t]{2}{*}{$B$} & \multirow[t]{2}{*}{ SE } & \multirow[t]{2}{*}{ Wald } & \multirow[t]{2}{*}{$P$-value } & \multirow[t]{2}{*}{$\operatorname{Exp}(B)$} & \multicolumn{2}{|c|}{$95 \% \mathrm{Cl}$ for $\operatorname{Exp}(B)$} \\
\hline & & & & & & Lower & Upper \\
\hline Constant & -2.09 & 0.75 & 7.68 & 0.01 & 0.12 & & \\
\hline Female (ref.: male) & 0.23 & 0.20 & 1.28 & 0.26 & 1.26 & 0.84 & 1.88 \\
\hline \multicolumn{8}{|l|}{ Age (ref.:18-39 years) } \\
\hline 40-64 years & 0.21 & 0.23 & 0.89 & 0.35 & 1.24 & 0.80 & 1.93 \\
\hline$\geqq 65$ years & 0.74 & 0.54 & 1.88 & 0.17 & 2.09 & 0.73 & 6.00 \\
\hline \multicolumn{8}{|l|}{ Education (ref.: primary school or below) } \\
\hline Secondary school & 1.05 & 0.52 & 4.08 & 0.04 & 2.87 & 1.03 & 8.00 \\
\hline Bachelor or above & 1.30 & 0.57 & 5.22 & 0.02 & 3.68 & 1.20 & 11.28 \\
\hline \multicolumn{8}{|l|}{ Marital status (ref. unmarried) } \\
\hline Married/ cohabited & -0.32 & 0.35 & 0.87 & 0.35 & 0.72 & 0.37 & 1.43 \\
\hline Separated/ divorced & 0.69 & 0.59 & 1.35 & 0.25 & 1.99 & 0.62 & 6.39 \\
\hline Widowed & 0.34 & 0.53 & 0.40 & 0.53 & 1.40 & 0.49 & 3.97 \\
\hline Children (ref.: none) & 0.02 & 0.31 & 0.00 & 0.95 & 1.02 & 0.55 & 1.87 \\
\hline \multicolumn{8}{|l|}{ Religious belief (ref.: none) } \\
\hline Christianity & -0.31 & 0.26 & 1.37 & 0.24 & 0.74 & 0.44 & 1.23 \\
\hline Buddhist/ Chinese folk beliefs & 0.38 & 0.23 & 2.85 & 0.09 & 1.47 & 0.94 & 2.29 \\
\hline \multicolumn{8}{|l|}{ Occupation (ref.: Disciplined services/ other) } \\
\hline Professional & 0.13 & 0.39 & 0.11 & 0.74 & 1.14 & 0.53 & 2.46 \\
\hline Medical (assistant) professional & 0.72 & 0.48 & 2.28 & 0.13 & 2.05 & 0.81 & 5.21 \\
\hline Technician & 0.23 & 0.43 & 0.29 & 0.59 & 1.26 & 0.54 & 2.93 \\
\hline Attendant & 0.22 & 0.43 & 0.25 & 0.62 & 1.24 & 0.53 & 2.89 \\
\hline Not employed & 0.38 & 0.47 & 0.65 & 0.42 & 1.46 & 0.58 & 3.65 \\
\hline \multicolumn{8}{|c|}{ Average monthly income in the past year (ref.: $<9,999)$} \\
\hline $10,000-19,999$ & 0.06 & 0.39 & 0.02 & 0.87 & 1.06 & 0.49 & 2.29 \\
\hline $20,000-29,999$ & -0.05 & 0.39 & 0.02 & 0.89 & 0.95 & 0.45 & 2.02 \\
\hline$\geqq 30,000$ & -0.31 & 0.39 & 0.62 & 0.43 & 0.73 & 0.34 & 1.58 \\
\hline Cared for relatives/ friends (ref.: no) & 0.27 & 0.19 & 2.10 & 0.15 & 1.31 & 0.91 & 1.88 \\
\hline Good Self-rated health (ref.: not good) & 0.17 & 0.19 & 0.78 & 0.38 & 1.18 & 0.81 & 1.72 \\
\hline Palliative care knowledge scores & 0.08 & 0.04 & 4.40 & 0.04 & 1.08 & 1.01 & 1.16 \\
\hline $\begin{array}{l}\text { Attitude towards life-sustaining treatments } \\
\text { (ref.: agree) }\end{array}$ & 1.18 & 0.18 & 41.43 & 0.00 & 3.27 & 2.28 & 4.69 \\
\hline
\end{tabular}

established a reliable examination enquiring residents' preference as well as identifying factors influencing such preference.

Macao has over 20 years of history of providing palliative and EoL care, however, revealed in this study is the lack of understanding people have regarding palliative care. Particularly, respondents believed palliative care is only for people with terminal cancer (see Table 3), and a large number of respondents perceived palliative care as a pessimistic way to wait for death (see Table 3). Results of this study share similarity with a study based in Hangzhou and Hong Kong, in that the majority of study respondents had not heard of palliative care [13-15]. The insufficient understanding regarding palliative and EoL care is also found in a number of other studies across different contexts such as Japan, China, Scotland, the United Kingdom and Italy [3, 5, 21-23].

Although the Chinese taboo relating to death and dying has cast a significant barrier in promoting palliative and EoL care, our study shows that over $62.0 \%$ of respondents in Macao preferred palliative care knowing that their lives might not be prolonged. The acceptance of palliative care found in our study also reflects in the Hangzhou study mentioned earlier [14]. Nevertheless, Macao residents consciously chose palliative care over LST with potential suffering, a significant number of residents still agreed that LST should never be stopped under any circumstances. The contradictory phenomenon is also observed in Taiwan wherein palliative care is relatively well established. Ranking the first amongst Asian regions, the 2015 Quality 
of Death index indicated that Taiwan has one of the best palliative and EoL care in the world [24]. Despite the fact that Taiwan has a dependable palliative care foundation, healthcare professionals continue to struggle with ethically challenged decisions in caring for terminal patients, such as the provision and withdrawal of LST for terminal patients $[25,26]$. On the other hand, owing to Macao's limited palliative care development since its first introduction, a significant number of respondents in this study still agreed that LST, as a clinical norm [27], should not be stopped under any circumstances, even though palliative care would have been their preferred EoL option. Besides, previous studies in Hong Kong found that people's understanding regarding LST was inadequate [15, 28, 29], and this finding may lend support to the conflicting wishes observed amongst the respondents of this study, indicating the public of Macao may also lack sufficient understanding regarding LST. Hence, the findings of our study reflect a need for public education on palliative care as well as LST, enabling people to better understand different types of care and treatments available, as well as the best suitable treatments for them at the end of their lives.

\section{Limitations}

The study has employed quota sampling to recruit sample respondents who would meet the demographic characteristics of the public of Macao, but the non-probability sampling was still a limitation. In addition, the study primarily collected data by way of online questionnaire survey, which may be related to the higher education tendency of participants in this study; both conditions could elicit selection bias in this study.

\section{Conclusions}

The current study found that people's understanding of palliative care is inadequate in Macao. Although the public of Macao gravitated towards comfort care over futile life prolongation, there was still a significant number of people who did not want LST to stop at the end of their lives. This conflicting treatment decision is, proposed by this study, not only related to the lack of understanding regarding palliative and EoL care, but also related to the insufficient knowledge about the specificities of LST offered in acute hospital setting. Being the first study in Macao to target the general population, results of this study suggest that there is a need to strengthen public education with respect to palliative care, EoL care and LST. In addition, it is equally important to encourage professional education on palliative care, in pursuit of equipping healthcare workers to support better and more appropriate end of life treatment decision making amongst patients and families.
Abbreviations

EOL: End of life; LST: Life-sustaining treatments.

\section{Supplementary Information}

The online version contains supplementary material available at https://doi. org/10.1186/s12904-021-00798-z.

Additional file 1

\section{Acknowledgements}

The authors would like to express their gratitude to all respondents and investigators who participated in this research; Federação das Associações dos Operários de Macau (FAOM) and União Geral das Associações dos Moradores de Macau for disseminating the research information; Centro de Dia "Brilho da vida", Centro de Dia da Ilha Verde, Centro de Dia de Mong Ha da FAOM, and Day Centre "Prazer para Idosos" of The Women's General Association of Macau for recruiting elderly participants.

\section{Authors' contributions}

K.I.T, S.L.C, S.M.L. and M.X.Z have contributed to the design of the work, the interpretation of data and the discussion of the study objectives. K.I.T. drafted and substantially revised the manuscript. S.L.C. contributed by analysing, interpreting the data and revising the manuscript. S.M.L. contributed by analysing, interpreting the data and substantially revising the manuscript. K.I.T, S.L.C, S.M.L. and M.X.Z have read and approved the final version of the manuscript.

\section{Funding}

The authors disclosed receipt of the following financial support for the research, authorship, and/or publication of this article: This research has received funding from the Higher Education Foundation of Macao (Reference number: HSS-KWNC-2020-01).

Availability of data and materials

Raw data may be obtained from the corresponding author on reasonable request.

\section{Declarations}

\section{Ethics approval and consent to participate}

The study obtained ethical approval from Kiang Wu Nursing College of Macau (Reference number: 20190CT01) on $28^{\text {th }}$ November 2019. Respondents were asked to give their consent prior to the commencement of the questionnaire survey. Respondents were explained that they could stop or withdraw from the survey any time.

\section{Consent for publication}

Not applicable.

\section{Competing interests}

The authors declared no potential conflicts of interest with respect to the research, authorship, and/or publication of this article.

Received: 1 March 2021 Accepted: 9 June 2021

Published online: 22 June 2021

References

1. Social Welfare Bureau. The 2016 - 2025 ten-year action plan for elderly services. In: Bureau SW, ed. Macao: Social Welfare Bureau; 2016.

2. Australian Government. Community attitudes towards palliative care. Canberra: Department of Health and Ageing; 2003 [Available from: http:// www.health.gov.au/internet/main/publishing.nsf/Content/palliativecarepubs-comm-attitudes.htm.

3. Hirai K, Kudo T, Akiyama M, Matoba M, Shiozaki M, Yamaki T, et al. Public awareness, knowledge of availability, and readiness for cancer palliative 
care services: a population-based survey across four regions in Japan. J Palliat Med. 2011;14(8):918-22.

4. Westerlund C, Tishelman C, Benkel I, Fürst CJ, Molander U, et al. Public awareness of palliative care in Sweden. Scand J Public Health. 2018;46(4):478-87.

5. Wallace J. Public awareness of palliative care: report of the findings of the first national survey in Scotland into public knowledge and understanding of palliative care. Scottish Partnership for Palliative Care; 2003.

6. Mcllfatrick S, Hasson F, McLaughlin D, Johnston G, Roulston A, Rutherford $L$, et al. Public awareness and attitudes toward palliative care in Northern Ireland. BMC Palliat Care. 2013;12(1):34.

7. ChungWongKiangChauLauWong RY-NEL-YNPY-KJYSY-S, et al. Knowledge, attitudes, and preferences of advance decisions, end-of-life care, and place of care and death in Hong Kong. A population-based telephone survey of 1067 adults. J Am Med Dir Assoc. 2017;18(4):367.e19-367.e27.

8. Benini F, Fabris M, Pace DS, Vernò V, Negro V, De Conno F, et al. Awareness, understanding and attitudes of Italians regarding palliative care. Ann Ist Super Sanita. 2011;47:253-9.

9. Weafer \& Associates Research. A nationwide survey of public attitudes and experiences regarding death and dying. Dublin: Weafer \& Associates Research; 2004 [Available from: https://hospicefoundation.ie/wp-conte nt/uploads/2012/04/Weafer-et-al-2004-A-nationwide-survey-of-publicattitudes-and-experiences-regarding-death-and-dying.pdf.

10. Shalev A, Phongtankuel V, Kozlov E, Shen MJ, Adelman RD, Reid MC Awareness and misperceptions of hospice and palliative care: a population-based survey study. Am J Hosp Palliat Med. 2018;35(3):431-9.

11. Sanjo M, Miyashita M, Morita T, Hirai K, Kawa M, Ashiya T, et al. Perceptions of specialized inpatient palliative care: a population-based survey in Japan. J Pain Symptom Manage. 2008;35(3):275-82.

12. Temel JS, Greer JA, Muzikansky A, Gallagher ER, Admane S, Jackson VA, et al. Early palliative care for patients with metastatic non-small-cell lung cancer. N Engl J Med. 2010;363(8):733-42.

13. The Federation of Medical Societies of Hong Kong. Survey on care for the advanced diseases. 2016 [Available from: https://www.fmshk.org/fmshk. html?id=737.

14. Xie Y, Xu Y, Yang S, Yan J, Jin XQ, Liu C. Investigation of the awareness of and demand for hospice care and attitudes towards life-sustaining treatment at the end of life among community residents in Hangzhou. BMC Palliat Care. 2020;19(1):1-9.

15. The University of Hong Kong. Community-wide survey on end-of-life care in Hong Kong 2016. Hong Kong; 2016.

16. Ho SW, Sanders GF. Preferences on end-of-life decisions among older Chinese in Macau. J Transcult Nurs. 2015;26(2):157-63.

17. Documentation and Information Centre of the Statistics and Census Service. Yearbook of statistics 2019. In: Service DalCotSaC, ed. Macao: Printing Bureau; 2020.
18. Charan J, Biswas T. How to calculate sample size for different study designs in medical research? Indian J Psychol Med. 2013;35(2):121.

19. Pourhoseingholi MA, Vahedi M, Rahimzadeh M. Sample size calculation in medical studies. Gastroenterol Hepatol Bed Bench. 2013;6(1):14.

20. Hsu C-P, Chen H-W, Lee S-Y, Tsou M-T. Knowledge and attitude toward hospice palliative care among community-dwelling aged Taiwaneseanalysis of related factors. Int J Gerontol. 2012;6(2):105-11.

21. Koffman J, Burke G, Dias A, Raval B, Byrne J, Gonzales J, et al. Demographic factors and awareness of palliative care and related services. Palliat Med. 2007;21(2):145-53.

22. Yamagishi A, Morita T, Miyashita M, Akizuki N, Kizawa Y, Shirahige Y, et al. Palliative care in Japan: current status and a nationwide challenge to improve palliative care by the cancer control act and the outreach palliative care trial of integrated regional model (OPTIM) study. Am J Hosp Palliat Med. 2008;25(5):412-8.

23. Zhu T, Zhang J, Shi Y, Yi J, Zhang Q, Zhao Y, Gao Q, Wang Z, Li J, Liu X, Liu D. Awareness and attitudes toward advance care planning among community-dwelling older adults in China: a mixed-methods study. Am 」 Hosp Palliat Care. 2020:1049909120905255.

24. TEI Unit. The 2015 quality of death index: ranking palliative care across the world. London: The Economist Intelligence Unit; 2015. p. 15.

25. Chiu T-Y, Hu W-Y, Huang H-L, Yao C-A, Chen C-Y. Prevailing ethical dilemmas in terminal care for patients with cancer in Taiwan. J Clin Oncol. 2009:27(24):3964-8.

26. Huang H-L, Yao C-A, Hu W-Y, Cheng S-Y, Hwang S-J, Chen C-D, et al. Prevailing ethical dilemmas encountered by physicians in terminal cancer care changed after the enactment of the natural death act: 15 years' follow-up survey. J Pain Symptom Manage. 2018;55(3):843-50.

27. Seymour J, Payne S, Chapman A, Holloway M. Hospice or home? Expectations of end-of-life care among white and Chinese older people in the UK. Sociol Health IIIn. 2007:29(6):872-90.

28. KwokT, Twinn S, Yan E. The attitudes of Chinese family caregivers of older people with dementia towards life sustaining treatments. J Adv Nurs. 2007:58(3):256-62.

29. Yun YH, Lee MK, Chang YJ, You CH, Kim S, Choi JS, et al. The life-sustaining treatments among cancer patients at end of life and the caregiver's experience and perspectives. Support Care Cancer. 2010;18(2):189-96.

\section{Publisher's Note}

Springer Nature remains neutral with regard to jurisdictional claims in published maps and institutional affiliations.

Ready to submit your research? Choose BMC and benefit from:

- fast, convenient online submission

- thorough peer review by experienced researchers in your field

- rapid publication on acceptance

- support for research data, including large and complex data types

- gold Open Access which fosters wider collaboration and increased citations

- maximum visibility for your research: over $100 \mathrm{M}$ website views per year

At BMC, research is always in progress.

Learn more biomedcentral.com/submissions 